\title{
O ovo da serpente? Fundamentos e variações da crítica ao componente conservador das "Jornadas de junho" de 2013
}

\author{
Pedro Luiz Lima ${ }^{1}$ \\ Mateus Hajime Fiori Sawamura²
}

\section{Resumo}

A fortuna das interpretações sobre junho de 2013, salvo relevantes exceções, parece-nos ter sido acometida por infrutífera polarização. De um lado, a ênfase nos aspectos positivos das mobilizações permanece aquém de construir uma plausível relação entre os eventos de 2013 e seus desdobramentos na arena político-institucional do país, tratando junho como evento alheio à reação conservadora que se the seguiu. De outro lado, a ênfase no polo negativo faz crer que ora se tratariam de manifestações com alto grau de superficialidade, como meros eventos performáticos e miméticos de uma forma global de mobilização; ora se trataria do gatilho de uma reação conservadora cuja retórica genérica sobre corrupção e patriotismo seria sintoma de uma pulsão fascista, antiinstitucional, anti-representação e, no limite, anti-democrática. Buscaremos identificar fundamentos e variações de algumas destas interpretações, em chave negativa, sobre o caráter conservador de junho de 2013 - menos para restituir imediatamente alguma verdade intrínseca que tais interpretações revelariam, e mais para entender como a polifonia e os antagonismos no interior deste restrito campo interpretativo apontariam, mesmo dados os limites de sua unilateralidade, para um momento crucial da efetiva contradição do fenômeno histórico em questão.

Palavras-chave: Conservadorismo. Fascismo. Protestos. Junho de 2013.

\begin{abstract}
The fortune of June 2013's interpretations, apart from relevant exceptions, seems to have been stricken by fruitless polarization. On one hand, the emphasis in positive aspects of the mobilizations remains short of constructing likely relationships between 2013's events and its unfolding at the political-institutional arena, discussing June as if it was unrelated to the following conservative backlash. On the other hand, the emphasis in negative aspects is founded in a twofold belief: sometimes there would be manifestations with a high level of superficiality. And sometimes those
\end{abstract}

\footnotetext{
${ }^{1}$ Professor Adjunto de Ciência Política na Universidade Federal do Rio de Janeiro (UFRJ), Brasil. Email: pedrollima@gmail.com.

2 Graduando de Ciências Sociais na Universidade Estadual de Londrina (UEL), Brasil. Email: mitchue.mateus@gmail.com.
} 
manifestations would be the catalyst of a conservative backlash whose generical rhetoric about corruption and patriotism would be mere symptoms of a fascist drive, anti-institutional, anti-representation and, at the limit, anti-democratic. We will seek to identify the bases and variations of some of these interpretations, in a negative key, about the alleged June 2013's conservative nature, not so much to immediately restitute some intrinsic truth that such interpretations would reveal. Rather, we shall try to understand the way through which polyphony and antagonisms within this restrict interpretation field do point, given its unilaterality's limits, to a crucial moment of the phenomenon's effective contradiction.

Keywords: Conservatism. Fascism. Protests. June 2013.

\section{Introdução ${ }^{3}$}

Hegel afirma, ainda no início da Fenomenologia do Espírito, que uma das dificuldades para a consciência que busca apreender a contradição residiria em "não sabe[r] geralmente libertá-la - ou mantê-la livre - de sua unilateralidade" (Hegel, 1995, p. 22). Diante da contradição, tenderíamos, portanto, a transpor a unilateralidade (Einseitigkeit) de nossas próprias consciências para a objetividade contraditória da realidade, destituindo-a de seu movimento interno (a contradição) e mantendo-nos distantes de sua dinâmica efetiva. O apego à unilateralidade implicaria, em outros termos, uma recaída na perspectiva simplória em que a partilha entre o verdadeiro e o falso se estabeleceria sem mediações. Esta demarcação estrita pertenceria aos pensamentos carentes-de-movimento (bewegungs/os), contra os quais Hegel defende que "a verdade não é uma moeda cunhada, pronta para ser entregue e embolsada sem mais" (Idem, p. 41). Para além de uma verdade ready-made, afirma-se a necessidade de compreendê-la como processo radicalmente ambivalente.

A ambivalência é, pois, constitutiva da história, cuja compreensão passa por desconfiar de meras positividades. A potência desta compreensão não se realiza, ainda nos termos hegelianos, "como um positivo que se afasta do negativo", mas apenas quando "encara diretamente o negativo e se demora junto dele" (Idem, p. 38). A

\footnotetext{
3 Gostaríamos de agradecer aos pareceristas, por sugestões e críticas que em muito ajudaram a aprimorar o artigo, e à Professora Fernanda Di Flora, cujos comentários a um primeiro esboço deste trabalho foram valiosos para entendermos suas potencialidades e limites. Cabe a nós, os autores, a responsabilidade exclusiva pela eventual persistência de lacunas e imprecisões.
} 
imediatez, a impaciência e a inquietude são termos frequentes no vocabulário de Hegel para depreciar as limitações do entendimento (Verstand) diante de uma razão (Vernunft) que "suporta as longas distâncias" e "demora-se em cada momento" (Idem, p. 36).

Retomando a primeira passagem hegeliana citada nesta introdução, libertar a contradição dos ímpetos unilaterais da consciência é determinante para almejar que, uma vez livre, se possa dialeticamente superá-la. A partir dos controversos eventos de Junho de 2013 no Brasil e de algumas de suas mais difundidas interpretações, este artigo busca "pôr em prática" as coordenadas hegelianas brevemente assinaladas acima com o fim de contribuir para uma mais densa compreensão daquele momento, tão impactante quanto obscurecido, da política brasileira contemporânea. Especificamente, trata-se de "demorar-se no negativo" e, em certo sentido, reconstituir a sua vigência como um correlato necessário da positividade, para que da unilateralidade vazia se possa passar à devida apreensão da contradição. Mais concretamente, a tentativa aqui será de identificar fundamentos e variações das interpretações, em chave negativa, sobre o caráter conservador de Junho de 2013 menos para restituir imediatamente alguma verdade intrínseca que tais interpretações revelariam, e mais para entender como a polifonia e os antagonismos no interior deste restrito campo interpretativo apontariam, mesmo em sua unilateral falsidade, para um momento crucial do verdadeiro.

A fortuna das interpretações sobre Junho de 2013, salvo relevantes exceções (Alonso, 2017; Alonso e Mische, 2016; Singer, 2013; Bringel, 2017; Bringel e Pleyers, 2015; Tatagiba, 2014; Tatagiba et alii, 2015), parece-nos ter sido acometida por infrutífera polarização. De um lado, a ênfase nos aspectos positivos das mobilizações permanece aquém de construir uma plausível relação entre os eventos de 2013 e seus desdobramentos na arena político-institucional do país. Louvar a horizontalidade, a autonomia dos movimentos sociais diante das rígidas estruturas partidárias, a organização através de redes, a ocupação multitudinária do espaço público, a emergência de demandas legítimas pela desmercantilização e desmilitarização da vida nas grandes cidades brasileiras, o pleito por transformações no sistema políticoeleitoral - tudo isso foi parte de Junho de 2013 , mas não esgota seu sentido. Seria 
impossível, a partir desta hipérbole da valência positiva dos eventos, sequer esboçar uma compreensão do vínculo histórico entre as mobilizações de 2013 e a cadeia de eventos que envolve (a) a criação da força-tarefa da Lava-Jato, (b) as mobilizações pelo impeachment de 2015 e 2016, (c) a efetivação do golpe parlamentar e (d) a caça judicial e extra-judicial ao Partido dos Trabalhadores e ao ex-presidente Lula.

A nosso ver, não é plausível simplesmente afirmar a desconexão entre os eventos, como se junho de 2013 estivesse a salvo dos desdobramentos históricos que contrariam a linearidade pré-estabelecida subjetivamente por seus apologetas de esquerda (Arantes, 2014; Safatle, 2017; Nobre, 2013; Moraes et alii, 2014; Ortellado, 2014), como se tudo o que se passou depois no plano político institucional fosse apenas reação, e não também derivação, da insurgência. De outro lado, a ênfase no polo negativo faz crer que ora se tratariam de manifestações com alto grau de superficialidade, como meros eventos performáticos e miméticos de uma forma global de mobilização; ora se trataria do início de uma reação conservadora cuja aparente luta contra a corrupção em nome das cores da pátria apenas esconderia o projeto de apear o PT do poder, enquadramento em que o apartidarismo aparece como mero sintoma do desejo de aniquilar a esquerda. Se esse viés pode ajudar a compreender os nexos entre 2013 e seus desdobramentos, ele subestima, contudo, a autenticidade do movimento e seu potencial de resistência, manifesto em eventos posteriores, ininteligíveis quando destituídos de seu nexo com junho, tais como a greve de garis durante o carnaval carioca de 2014 e o movimento de ocupação das escolas pelos secundaristas, em escala nacional, nos dois anos seguintes.

Distante da pretensão de dissolver as controvérsias sobre junho e seus efeitos, o esforço aqui empreendido vai no sentido de buscar restituir a contradição. Mesmo para este fim, trata-se de uma investida parcial e indireta, compatível com os limites deste artigo. Parcial, pois investigaremos apenas o polo negativo das narrativas unilaterais sobre junho; indireta, pois acessaremos o evento histórico através da mediação daquelas narrativas, caminho pelo qual acreditamos ser possível, pela análise crítica desta unilateralidade, compor um quadro mais complexo sobre o evento 
e seus desdobramentos, uma vez que, desde sempre, junho de 2013 é constituído pelas representações que se fazem dos eventos.

Em um primeiro momento, abordaremos as interpretações de Marilena Chauí e Jessé Souza, a partir das quais importará reconstituir pontos de partida distintos, e por vezes antagônicos, no que tange a suas interpretações do Brasil, mas que resultariam em diagnósticos muito próximos sobre o eventual "fascismo" de junho. Na sequência, passaremos a perspectivas elaboradas no campo específico da Ciência Política, em que a convergência aparente de interpretações entre Leonardo Avritzer e Fabiano Santos também se fundaria em uma diversidade de fundamentações que cumprirá identificar. Nas perspectivas mais abrangentes, sociológicas e filosóficas, assim como naquelas mais diretamente preocupadas com a democracia entendida em seu plano institucional, o conservadorismo atribuído a junho aparece nos discursos como efeito de um longevo legado histórico-social e como um atentado contra a ampliação da presença dos mais pobres em redutos antes reservados a pequena fração privilegiada da população. O sentido fascista emerge a partir das mais diversas premissas, do espinozismo ao institucionalismo, de adeptos da teoria do Brasil patrimonialista a seus mais ferozes críticos, de participacionistas a defensores ardorosos da democracia representativa - o que ensina algo sobre junho de 2013 e, certamente, também sobre o debate público no âmbito da esquerda brasileira. Como se verá no que segue, as avaliações em chave negativa aproximam conceitos significativamente distintos entre si - conservadorismo, autoritarismo, fascismo - reverberando no contexto acadêmico certas indistinções próprias do registro discursivo do proselitismo político. Acompanhar de perto a retórica dos autores elencados e os modos pelos quais mobilizam os conceitos propiciará uma perspectiva mais aguda sobre as consequências de tais indistinções.

\section{Interpretações do Brasil, dinâmica de classes e reviravoltas do}

\section{autoritarismo}

Jessé Souza e Marilena Chauí foram dois dos intelectuais que mais se fizeram ouvir, de modo inequívoco, na esfera pública nacional no contexto das manifestações 
de junho e, depois, quando da crise que culminou no golpe parlamentar de 2016. Ambos alinharam-se no campo dos críticos de junho e da defesa da democracia contra o golpe. Tanto Chauí, quanto Souza, incorporam em suas análises conjunturais a amplitude de suas obras pregressas, em que a preocupação com a formação histórica do Brasil e suas vicissitudes ocupa lugar central. Nesse sentido, é menos pelo discurso competente de experts em áreas específicas, afetadas diretamente pelos eventos, que eles se pronunciam, e mais enquanto intérpretes do Brasil. Por isso, partiremos aqui também de alguns traços gerais de suas interpretações da formação sócio-histórica do país - precisamente porque é neste ponto em que incidem as divergências que importa salientar.

A obra recente de Jessé Souza $(2015,2016,2017)$ pode ser lida como um esforço de "popularização" de sua disputa contra o que chama de "tese do patrimonialismo brasileiro". Sua desconstrução deste persistente paradigma de interpretação se realiza, contudo, desde antes - e, a nosso ver, ela aparece mais bem acabada em obras dissociadas da conjuntura imediata que nos importa. Em "Modernização seletiva" (2000) e "A construção social da subcidadania" (2003), destituído da verve de polemista inflamado que o tem caracterizado desde os eventos de 2013, Souza constrói sólida argumentação sobre os limites da ideia de que o "atraso" da sociedade brasileira se deveria a um patrimonialismo renitente, que nos impediria de avançar rumo à equiparação com as sociedades propriamente modernas. Para Jessé Souza, a tese do patrimonialismo seria ela própria um dos verdadeiros obstáculos à luta primordial contra a desigualdade, daí revestir-se sua sociologia de um componente de denúncia, no terreno da esfera pública, à difusão viciosa daquela tese.

O sociólogo trava ainda outra disputa, desta vez para fazer contraponto a obras acadêmicas e a uma corrente de opinião que tematizou a expansão do poder de consumo dos mais pobres no país como a emergência de uma "nova classe média" (Neri, 2010). Para Souza, tratava-se, antes, da ascensão, ainda que estruturalmente limitada, de uma classe que ele denominou como "batalhadores" (Souza, 2009). A ênfase no fato de que se trata de uma nova classe de trabalhadores, e não de uma 
incorporação à classe média, ilustra o sentido da disputa que, antes de ser estatística ou analítica, era eminentemente política.

Através destas disputas, panoramicamente descritas acima, chegamos a junho de 2013. O sentido geral de sua argumentação recente está em mostrar como junho deve ser entendido como o "ovo da serpente" da reação conservadora no país. Para isso, ele adota uma comum distinção entre duas fases das manifestações: o início dos atos, em que havia mais "batalhadores" e jovens pobres nas ruas; e um segundo momento, em que a "classe média tradicional" teria assumido o sentido das manifestações.

A tese das duas fases é determinante no argumento de Souza, uma vez que este se baseia numa suposta "manipulação" do sentido originário das manifestações. O que aparece inicialmente como uma "aliança entre estudantes e 'batalhadores' da classe trabalhadora precária (...) por uma pauta de reivindicações em consonância com os interesses das classes populares" teria, em pouco tempo, se "federalizado" e se transformado em manifestações massificadas, com o apoio da mídia nacional e o “inconteste protagonismo" da classe média (Souza, 2015, p. 240). Com a construção deste hiato entre os dois momentos, parece-nos que Souza a um só tempo salvaguarda o potencial sentido progressista originário dos primeiros movimentos de junho de 2013, enquanto busca ressaltar o caráter "manipulatório" que adultera a dinâmica das manifestações. É interessante observar que esta versão dos fatos ainda parece restituir a ambivalência do fenômeno histórico, mas o faz às custas de separar as valências no tempo e de distinguir precisamente seus portadores - a positiva teria vindo antes, expressada por jovens estudantes e "batalhadores", enquanto a negativa viria depois pelas mãos da mídia manipuladora e da classe média tradicional.

Mesmo este pálido reconhecimento do caráter contraditório dos eventos de junho não subsiste no centro da argumentação do autor. Para denunciar o caráter mistificador e conservador dos acontecimentos, "junho de 2013" passa a ser identificado na análise de Jessé Souza como sinônimo deste segundo momento - e a primeira fase parece tacitamente desaparecer diante do "ponto de inflexão fundamental" do dia 19 de junho (Souza, 2015, p. 240). É apenas por conta deste desaparecimento da versão progressista de junho que o autor pode enunciar 
afirmações taxativas como a seguinte: "existe uma clara linha de continuidade entre as glorificadas e midiaticamente manipuladas manifestações de junho de 2013 e o golpe de abril de 2016" (Souza, 2016, p. 87). Por decerto, a linha de continuidade, que deve mesmo ser estabelecida, tal como afirmamos na introdução acima, torna-se mais "clara" quando se retiram do diagnóstico os fatores que contradiriam tal linearidade. Em outros termos, Souza promete uma aguda reconstituição daquela continuidade, mas o faz com excesso de linearidade, perdendo de vista assim a complexidade contraditória da sequência de acontecimentos.

A tese da manipulação midiática do sentido das manifestações se combina, no texto de Souza, não sem alguma tensão, com o protagonismo da classe média. Combinação tensa, porque pela caracterização que é feita da classe média e de seus atributos intrínsecos não parece haver sentido em falar de manipulação pelo alto, pois o que ocorreria seria uma manifestação conservadora de uma classe eminentemente conservadora - não havendo, portanto, o que manipular. O vínculo entre junho de 2013 e o golpe de 2016 se estabelece, nos termos de Jessé Souza, sempre como efeito de um "conluio", de "manipulação", de "cooptação". Mas, curiosamente, ele mesmo nos ensina que a "velha classe média conservadora" é a portadora perversa de um "racismo de classe" e que ela "sempre desprezou e odiou os pobres" (Souza, 2016, pp. 96, 97 e 100). Neste passo da reconstrução histórica, o que era protagonismo se transforma em mera ilusão, e a classe média passa a ser a entidade passiva sobre a qual se depositavam os interesses objetivos da elite. Estranhamente, para o predomínio do "caráter antipolítico do movimento", teria sido preciso "incutir nessa fração de classe o sentimento de protagonismo no movimento, ainda que, na verdade, fosse mero instrumento de manipulação do consórcio elites/mídia" (Souza, 2016, pp. 99 e 101).

Fato é que, nesta peculiar dinâmica, movida tanto pelo ódio espontâneo de classe quanto pelos interesses impublicáveis de outros atores, a classe média teria feito desvanecer qualquer sentido originário anterior à sua chegada em cena, pela hipóstase da luta contra a corrupção e do sentimento de aversão aos partidos 
políticos. Mais uma vez, que essa aversão estivesse, em junho, vinculada a um conteúdo social mais ambivalente, presente também na recusa de novos movimentos sociais e de grupos anarquistas vis-à-vis a organização política de tipo tradicional, e que ela não fosse, portanto, apenas sintoma de um conservadorismo atávico - isso não chega a constar na avaliação do autor. Tudo não passaria de "uma máscara da velha e surrada rejeição conservadora e antidemocrática à política vista como suja e corrupta" (Souza, 2016, p. 100).

O discurso anticorrupção, alçado a topos prioritário dos protestos pela classe média e pela mídia manipuladora, veio acompanhado da estética ufanista. Retomando um alinhamento cromático clássico da política nacional, o verde-e-amarelo voltou-se violentamente contra o vermelho da esquerda em geral, de petistas em particular, e ainda de comunistas, imaginários ou reais. Neste ponto, junho de 2013 estaria às raias do fascismo, com o Brasil sendo utilizado retoricamente como o "partido dos homens de bem" contra os partidos vermelhos que buscariam dividir a pátria: "o ufanismo do país indiviso que não tolera a diversidade e ao mesmo tempo se põe como único representante da nação [constitui] um protofascismo óbvio" (Souza, 2016, p. 101).

Ainda que construída em chave excessivamente conspiratória, o que destitui em parte a verossimilhança da descrição de Souza, é importante seu apontamento sobre o nexo entre a emergência da demanda pela derrubada da Proposta de Emenda Constitucional que retiraria funções investigativas do Ministério Público (a célebre "PEC 37") e o início de um processo de intensa associação entre as instituições judiciais e a mídia corporativa no país. Pensada como um "conluio entre mídia e o aparelho jurídico-policial do Estado" (Souza, 2016, p. 95), perde-se de vista talvez aquilo que mais importe na conjuntura política recente: este "conluio", com efeito, se realiza não como aliança secreta, e sim como efeito de uma convergência concreta de interesses que pode dispensar conspiratas e que se manifesta, sem quaisquer pudores, pública e abertamente.

Pela ênfase na pauta da corrupção, pela aversão aos partidos políticos, pela adesão protofascista aos atores judiciais responsáveis por sanear a nação, as manifestações seriam veículos, e efeitos, da difusão pública da tese do patrimonialismo. A aversão à política se confundiria com a estadofobia, o que se 
combinaria, um tanto paradoxalmente, com a adesão maciça da classe média ao braço do Estado (as forças judiciais) que, essencialmente imunizado contra vícios políticos, deveria ser o responsável pela correção virtuosa de rumos da vida política nacional, perseguindo e punindo as práticas personalistas do patrimonialismo reinante. Assim teriam sido lançadas, em junho de 2013, as bases da reação conservadora que culminaria com o golpe de 2016.

Do mesmo modo que é curiosa a estadofobia que precisa fazer apelo ao "aparelho jurídico-policial do Estado" para se concretizar, também nos parece intrigante que o sociólogo celebrizado por sua incansável denúncia das perversidades da tese do patrimonialismo para a reflexividade média nacional precise lançar mão de "conluios", "cooptações" e "manipulações" para explicar a reação conservadora. Mais especificamente, parece destoar da defesa intransigente do caráter moderno e capitalista das relações sociais no Brasil a afirmação da existência de uma "casta jurídica" (Souza, 2016, p. 105), categoria que aparece com frequência para designar, talvez, o novo nome dos donos do poder. Assim, a frequente remissão às forças conspiratórias por trás da reação que se iniciaria em junho de 2013 parece descuidar das contradições efetivas de um momento histórico em que a luta de classes, ao menos por parte dos de cima, se travou de maneira inconfundível - e esse descuido pode ter implicado a atribuição de um papel excessivamente desmistificador e desvelador ao analista de conjuntura, que o impeliria às raias de uma versão autoritária da própria função, quando "um país de pessoas inteligentes [se torna] uma multidão de tolos manipulados e incapazes de perceber o próprio interesse real" (Souza, 2015, p. 252). Atribuindo-se a si mesmo o monopólio do acesso à verdade, o intelectual não apenas desliza para um antiquado plano de infalibilidade, como também arrisca deixar de escutar o sentido das disputas enquanto estas se travam no âmbito necessariamente ruidoso das ruas.

Outra voz incisiva que se levantou, a partir da esquerda, para uma análise crítica das manifestações de junho de 2013 foi a da filósofa Marilena Chauí. Se, como vimos, a assim chamada "escola paulista", formada ao redor da USP, é um dos alvos 
preferenciais dos ataques de Jessé Souza, não seria de todo irrazoável alinhar Chauí dentre os seus porta-vozes. Ainda que tal "escola" se origine e circule em torno da área de sociologia, é certo que quando Marilena Chauí se aventura no campo da interpretação do Brasil, não deixa de reproduzir alguns traços daquele discurso consagrado, ainda que ela institucionalmente se situe na área da filosofia. Tanto Souza quanto Chauí, a despeito do desencontro de suas premissas, parecem convergir quanto à avaliação do componente autoritário, antidemocrático e até mesmo fascista dos eventos de junho de 2013 e de seus desdobramentos. Mas enquanto, no caso já analisado do pensamento de Jessé Souza, a reviravolta faz com que o ponto de partida radicalmente "anti-patrimonialista" e "anti-faoriano" dê lugar a uma concepção que, em grande medida, restitui o poder a uma dinâmica estamental (seja com a "casta jurídica", seja com a ênfase em manipulações e conluios); no caso de Chauí, a reviravolta consistirá em partir de uma leitura da história política do Brasil, e especialmente da história da esquerda no país, como "terra arrasada" até a emergência do PT, para na sequência, tratando de junho, adotar a postura de enquadrar os desafios e excessos dos manifestantes como gestos autoritários e fascistas, em defesa da ordem institucional. Em outros termos, o desafio que o PT lançou à ordem, nos anos 1980, seria legítimo, mas, trinta anos depois, a recusa da ordem pelos manifestantes, inclusive aqueles à esquerda do PT, seria superficial e essencialmente conservadora por não reconhecer o imperativo das mediações. Cabe observar mais de perto como esta reviravolta se consuma no pensamento da autora.

Em diversos de seus escritos, Chauí enfatiza o caráter autoritário da sociedade brasileira. Com isso, pretende contornar um diagnóstico que concentraria no Estado e em sua hipertrofia a origem das mazelas sociais do país. Este cuidado em difundir para além do Estado a dinâmica da sociabilidade autoritária contribui, de acordo com a célebre tipologia formulada em artigo seminal de Werneck Vianna, para incluir Chauí no rol dos adeptos de uma concepção do patrimonialismo societal (Vianna, 1999). Escrevendo em 1986, Chauí evidencia sua adesão a uma avaliação de que o Brasil estaria num horizonte pré-liberal: “O Brasil é uma sociedade autoritária, na medida em que não consegue concretizar sequer os princípios (velhos de três séculos) do liberalismo e do republicanismo. Indistinção entre o público e o privado, incapacidade 
para tolerar o princípio formal e abstrato da igualdade perante a lei, combate da classe dominante às ideias gerais contidas na Declaração dos Direitos do Homem e do Cidadão (...)" (Chauí, 1986, p. 47). Tal análise, em chave clássica que sublinha as ausências de nossa formação, se combina, na obra da filósofa, com a própria denúncia do "hábito de descrever, explicar e interpretar o Brasil pelo que lhe falta e não pelo que o constitui" (Chauí, 2013a, p. 226). Atenta aos limites de uma interpretação em chave puramente negativa, importa a Chauí perceber que "é a sociedade brasileira que é autoritária e que dela provêm as diversas manifestações do autoritarismo político" (Idem).

A ênfase no "autoritarismo social" induz a uma concepção da esfera política como mera instância de reprodução deste atraso originário. A recusa da história política do país como mera reprodução autoritária da sociabilidade herdada da escravidão que, como já notamos, conheceria uma novidade apenas quando da emergência do PT - tal recusa leva Chauí a formular uma leitura da história dos partidos políticos significativamente próxima à própria autoimagem que marca o nascimento do Partido dos Trabalhadores no início dos anos 1980. A grande narrativa da "terra arrasada" aparece, por exemplo, na longa, porém valiosa, passagem a seguir:

tem-se uma pista para compreender por que os partidos políticos são associações de famílias rivais ou clubsprivés das oligarquias regionais. Esses partidos arrebanham a classe média regional e nacional em torno do imaginário autoritário, isto é, da ordem, e do imaginário providencialista, isto é, o progresso. Mantêm com os eleitores quatro tipos principais de relações: a de cooptação, a de favor e clientela, a de tutela e a da promessa salvacionista ou messiânica (Chauí, 2013a, p. 230-231).

Não é coincidência, portanto, que sua interpretação do Brasil caminhe de par com a que foi defendida pelo principal formulador das hostes intelectuais que viriam a fundar o PT, Francisco Weffort. Mantendo o paralelo com Jessé Souza, importa salientar que se este é crítico contumaz da categoria do "populismo", Chauí, por seu turno, argumenta na esteira da "teoria do populismo" formulada por Weffort quando defende que "nessa sociedade não existem nem a ideia nem a prática da representação política" (Chauí, 1986, p. 55). Onde os partidos "sempre" são clientelistas, populistas ou vanguardistas, mesmo o mínimo liberal de 
representatividade aparece como se fosse um conteúdo utópico inatingível. E, para adentrarmos de uma vez no conteúdo das intervenções de Chauí sobre junho de 2013, não deixa de ser curioso que ela argumente, em textos dos anos 1980 e do início dos anos 2000, contra o autoritarismo da classe média e as mistificações do populismo, em defesa "das mediações políticas institucionais" (Chauí, 2013a, p. 224).

Sua análise de junho de 2013 passa necessariamente por um diagnóstico acerca da dinâmica de classes no país, a partir do qual ela atesta certas invariantes da ideologia da classe média e a emergência de uma "nova classe trabalhadora" suscetível de ser arrastada para a corrente conservadora em tempos de individualismo neoliberal triunfante. Sobre a classe média, uma de suas falas que mais reverberaram na esfera pública versou sobre a "tripla abominação" que lhe seria constitutiva: "abominação política, porque é fascista; abominação ética, porque é violenta; e abominação cognitiva, pois ela é ignorante" (Chauí, 2013b). Reativa diante dos avanços promovidos no período lulista, a classe média, segundo Chauí, não determinaria sozinha o caráter conservador de junho. Como em Souza, também aqui a percepção da mídia como um ator manipulador é constante; porém, mais do que esta aliança, relativamente corriqueira, entre grande mídia e classe média, o que importa assinalar é que mesmo a "nova classe trabalhadora" jogaria água no moinho da reação. Ainda em consonância com a sociologia de Jessé Souza, para Chauí é crucial apontar para as falsas detecções de uma "nova classe média" - tratar-se-ia de uma "nova classe trabalhadora", o que a situaria em um outro plano, com relação ao conservadorismo atávico de que aquela seria portadora privilegiada. Contudo, haveria um fenômeno de "absorção ideológica" que potencialmente lançaria os novos trabalhadores na esfera de influência da classe média. Segundo Chauí, uma vez que se constitui "no interior do momento neoliberal do capitalismo" e que não criou "formas de organização e de expressão pública", nada assegura que a nova classe trabalhadora resistiria espontaneamente à sua "absorção ideológica pelo imaginário da classe média" (Chauí, 2013c, pp. 99-100). Seja na adesão a uma secular "ideologia do empreendedorismo", seja na reprodução da versão pentecostal da "teologia da prosperidade", estariam os novos trabalhadores na contraditória condição de potenciais portadores da visão-de-mundo que teria passado 
a se expressar raivosamente, pela classe média, precisamente como reação à sua ascensão social.

De todo modo, a despeito do protagonismo da classe média e da ambivalente e "cooptável" nova classe trabalhadora, junho de 2013 seria menos um movimento de classe do que de massa. O horizonte individualista neoliberal, potencializado pela mediação das redes sociais - mediação indiferenciada e "invisível" por excelência -, teria transformado os protestos em "espetáculos de massa", em que a superficialidade do caráter efêmero dos atos associada ao estímulo pela "satisfação imediata do desejo" levaria ao esvaziamento de seu sentido político (Chauí, 2013d, pp. 2-3).

A mediação das redes sociais como catalisadoras dos protestos detém centralidade no argumento de Chauí. Essa "mediação evanescente" alimentaria uma lógica imediatista de satisfação de desejos que, em última instância, potencializaria o que ela chama de "pensamento mágico", alavanca para a aversão aos partidos políticos e à institucionalidade como um todo. Recusar "a legitimidade do partido político como instituição republicana e democrática" (Idem, p. 4) seria, para Chauí, equivalente a "desvalorizar a política" e a abolir qualquer tipo de mediação em nome da lógica pueril dos desejos imediatistas. Com este passo, a filósofa pode manter em segundo plano a diferença, indicada por ela mesma, entre o ponto de partida ("a luta pela revogação da tarifa") e o ponto de chegada ("crítica da política") de junho de 2013 - o que a impele, num passo adiante, a aproximar esta crítica da política à mera reprodução da "ideologia típica da classe média, que aspira por governos sem mediações institucionais e, portanto, ditatoriais" (Idem, p. 6). Assim, a atuação do Movimento Passe Livre (MPL) que inaugura os protestos de junho é lançada a um plano de equivalência com o verde-amarelismo da posteriormente hegemônica luta contra a corrupção, dado que esta seria apenas uma forma nuançada da mesma manifestação de um difuso sentimento anti-política.

Distante, pois, das virtualidades de um contexto de "invenção democrática", em que se fortaleceriam as instâncias de participação e representação, junho de 2013 sinalizaria um momento de hegemonia da "ideologia conservadora e midiática" que 
concebe a política tout court como sendo uma instância de corrupção (Idem, p. 5). Para Chauí, a deriva autoritária de junho residiria num jogo de afinidades eletivas entre ao menos três diferentes atores: em primeiro lugar, por suposto, um ator composto formado pela classe média, a grande mídia e os elementos neoliberais da "nova classe trabalhadora", seduzidos pelo encantamento das redes; em segundo lugar, os próprios movimentos sociais emergentes, como o MPL, cuja adesão a princípios anarquistas de horizontalidade radical dificultaria a definição de estratégias, sem as quais se tornariam presas fáceis da "apropriação e manipulação pela direita" (2013b); em terceiro lugar, também os adeptos da tática "black block" atuariam num sentido fascista, por esvaziarem seus atos violentos de qualquer direcionamento estratégico (2013d). O último tópico, externado por Chauí em palestra que tinha como público policiais recém-formados do Rio de Janeiro, também foi das falas que mais reverberaram na esfera pública.

A "recusa da política", atribuída indiscriminadamente aos manifestantes de junho, aparece em Chauí como o avesso das conquistas históricas dos movimentos sociais de fins dos anos 1970 e inícios dos 1980: enquanto antes se tratavam de "sindicatos, associações, entidades, movimentos sociais e populares [que] eram políticos, valorizavam a política, propunham mudanças políticas e rumaram para a criação de partidos políticos como mediadores institucionais de suas demandas" (Chauí, 2013d, p. 1), agora o que predominaria é o caldo de cultura anti-institucional, que a filósofa remete aos contextos clássicos de emergência do fascismo, na Itália dos anos 1920, e do nazismo, na Alemanha dos anos 1930 (Chauí, 2013b). O golpe de 2016 seria, nesse sentido, uma continuidade de junho de 2013 - um composto de sentimentos genuínos (ainda que equivocados) de recusa da política atrelados às artimanhas manipulatórias da mídia e da direita organizada (Chauí, 2016, p. 22).

Enquanto boa parte da esquerda, seduzida com a ocupação das ruas e embalada por concepções locais e estrangeiras acerca das maravilhas da sociedade em rede (Castells, 2013) e da positividade intrínseca da multidão (Negri e Hardt, 2004), teria ignorado este suposto "ovo da serpente", Chauí esteve desde o início cerrando fileiras no campo da desconfiança com relação aos desdobramentos de junho de 2013. 
Para esta peculiar convergência, aqui estabelecida, entre a filósofa espinosista uspiana e o sociólogo bourdieusiano "anti-patrimonialista", interessa o argumento doutrinário que ela mobiliza para se afastar de uma positivação automática das manifestações:

\begin{abstract}
A multitudo espinosana é, ao mesmo tempo, a guardiã da democracia e o maior perigo contra a democracia. Essa contradição é o coração da política. Já a multitudo de Negri não tem conflitos, não é travejada por paixões, não é contraditória, mas inteiramente positiva. (...) Eu digo que as paixões não têm freios, e quando elas estão ligadas à forma da propriedade e ao exercício do governo, você tem de realmente segurar a explosão passional ilimitada. (Chauí, 2013b).
\end{abstract}

Nada assegura, a priori, que a política multitudinária seja progressista. O século XX está, ademais, repleto de exemplos desta potencialidade conservadora das multidões. No caso do Brasil contemporâneo, Chauí parece retomar a clássica premissa da distinção entre classe e massa, atribuindo (a) à incompreensão da verdadeira luta de classes, (b) à sedução pelo discurso individualista neoliberal, (c) ao encantamento com as ilusões do espontaneísmo via redes e (d) à cooptação de frações da classe trabalhadora pelas forças conservadoras as causas da evasão da "invenção democrática" rumo ao plano dos "espetáculos de massa".

\title{
2. A caixa de Pandora da participação: a "equação fascista" e a
} antipolítica como o avesso da representação

Diversos são os analistas de conjuntura que, ao debruçarem-se sobre Junho, encontram tanto críticas sendo direcionadas às instituições representativas - "não me representa" -, quanto motivos para teorizar sobre a razoabilidade desta. Fabiano Santos e Leonardo Avritzer, ainda que formulem diagnósticos distintos, preocupam-se em comparar essas críticas com os saldos concretos das políticas de participação social do recente período democrático brasileiro. Outra questão que é fruto de inúmeras análises reside na maneira como os atores ditos relevantes se relacionam com a forma dos protestos ocorridos no mês de junho: as formas de convocação, organização, contenda e expressão da indignação. Nessa questão, é inevitável que os pensadores tracem conexões, ou cisões, entre as manifestações iniciais, que gravitavam em torno 
do MPL, e a posterior difusão de pautas e atores das manifestações (Santos, 2013; Avritzer, 2016; Haddad, 2017; Ortellado, 2014; Bucci, 2016).

O principal alvo da indignação difusa presente nas manifestações de junho de 2013, segundo Fabiano Santos, é a política representativa. Para ele, após o atendimento da pauta inicial (contra o aumento da passagem de ônibus), passam a adquirir contornos definidos e se espalhar pela "common parlance" discursos que localizam as fontes do mal-estar e dos entraves do país em tudo aquilo que é político instituições políticas, partidos políticos e políticos profissionais (2013a). São discursos simples e primários, seja por relacionar estritamente política e corrupção, colocando as instituições formais de controle como baluartes da justiça e da idoneidade, seja por atribuir diretamente os desvios da política ao voto popular, relacionando a massificação do voto à incapacidade de escolher representantes. Nas palavras de Santos, esses discursos compõem a "equação fascista", uma atitude política autoritária, intolerante à pluralidade de opiniões e interesses existentes na sociedade, que operaria segundo lógicas primitivas de não reconhecimento. Assentada sobre uma relação simplista, que arbitrariamente atribui equivalência entre duas variáveis ${ }^{4}, a$ “equação fascista” não reconhece práticas, opiniões e orientações político-ideológicas divergentes da sua.

Nos textos em que trata mais diretamente da conjuntura posterior, Santos (2016, 2017) parece apontar para a resolução de uma questão que levantara no momento em que as manifestações surgiram. No momento da difusão de pautas em junho, percebe-se a presença - dentro daquela multidão disforme - de setores da classe média que estariam órfãos de alternativas políticas à direita (2013a). Ao tratar do impeachment, que foi em suas palavras uma "peça sem autor" ${ }^{5}$, Santos narra algumas confluências entre o PSDB e os movimentos pró-impeachment. O PSDB, que tinha os setores da classe média como seu "core voters", sentiu-se compelido a se aproximar dos movimentos pró-impeachment (MBL e Vem Pra Rua) que vinham

\footnotetext{
${ }^{4}$ Santos apresenta alguns exemplos: associação entre os gastos direcionados para a realização de eventos esportivos mundiais e a má qualidade de serviços públicos universais, como a saúde e a educação; ou então, a indiferenciação entre a política e a corrupção.

${ }^{5}$ Uma peça em que não há um autor específico acompanhando e influenciando cada "ato". Uma farsa na qual cada ator por vez toma o posto de protagonista, percebendo-se ao fim na forma de golpe parlamentar (Santos, 2016).
} 
mobilizando esses setores às ruas, aderindo de vez a uma agenda conservadora e assumindo o papel principal na realização do impeachment - principalmente após o afastamento do Eduardo Cunha, até então central na "peça". Dessa forma, haveria na atual conjuntura diversos sinais que atestam a disseminação da lógica fascista pela classe média, pelos novos movimentos supra e apartidários e pela agenda conservadora no plano político institucional.

É importante salientar o caráter descomplexificado dessa lógica "fascista" e o quanto esta vai na contramão da concepção que Santos tem a respeito da representação democrática. Em texto escrito com Thamy Pogrebinschi (2011), ele parte da premissa de que nas sociedades contemporâneas a mediação é o horizontelimite da participação. Dessa forma, tanto a participação, quanto a deliberação responderiam ao mesmo conteúdo semântico da representação, que é tornar as deliberações mais próximas dos cidadãos, seja no conteúdo final, seja no controle do processo.

Nesse sentido, qualquer aprofundamento no campo da participação só seria possível pela complexificação dos processos representativos. Assim, o vetor desse aprofundamento não residiria no fato estrito de resultar numa ausência de mediação, mas sim no aumento da qualidade, na especialização dos temas e na possibilidade de alteração das preferências dos cidadãos ao longo do processo político. Dito isso, é possível inferir que a "equação fascista" atribuída por Santos a junho de 2013 possui um conteúdo semântico oposto àquele da representação e da participação, pois em vez de institucionalizar a pluralidade, ela mobilizaria discursos lineares, que não reconhecem práticas, opiniões e orientações político-ideológicas divergentes da sua.

Leonardo Avritzer, por sua vez, não repele tão veementemente a indignação e o mal-estar propalados pelos manifestantes. Na sua visão, a democracia brasileira demonstrou grandes saltos qualitativos em relação ao período autoritário. Por volta de 2013, porém, ela teria começado a esboçar impasses no exercício da oposição, no presidencialismo de coalizão, na participação social e no combate a corrupção. Apesar de ser capaz de gerar governabilidade no sentido de produção de decisões, o 
presidencialismo de coalizão viria enfrentando uma perda de legitimidade diante da opinião pública e dos setores de classe média devido ao alto custo de formar coalizões (fragmentação partidária e uso de cargos e recursos públicos como moeda de troca), o que, por fim, aumentaria a propensão à corrupção (2016a, p.84; 2016b, p.42).

Avritzer percebe, portanto, impasses que também têm lugar no âmbito institucional e que demonstram os empecilhos para um aprofundamento democrático, ao contrário de Santos, que enxerga no modelo de governança brasileiro uma estrutura inabalada e exterior aos atores que dela se utilizam. Tal diferença se mostra significativa quando contrastamos o que Junho de 2013 e o impeachment representam, na visão de cada um, para o sistema político. Se em Avritzer ambos são sinais da deslegitimação do sistema político e, respectivamente, dos impasses da governabilidade (2013a) e do equilíbrio de poderes político-institucionais (2017); em Santos, ainda que sejam sinais de conflitos políticos, eles não desbotaram a resiliência do modelo institucional.

Um segundo limite relevante para compreender a descrença nas instituições políticas pode ser detectado nos limites da participação social, que é, segundo Avritzer, o ponto de partida das manifestações de junho de 2013. Desde o período de redemocratização, a participação social institucionalizada vinha sendo reforçada no plano local e principalmente no federal - a partir da posse de Lula -, apresentando resultados positivos na forma dos Orçamentos Participativos, das inúmeras Conferências Nacionais e dos movimentos sociais do período de democratização que se institucionalizaram. No entanto, os limites se evidenciariam pela ausência da participação em áreas importantes como a infraestrutura, e no fato de não se ter incluído alguns setores da sociedade, como a classe média. De início, tais limites se mostravam solucionáveis dentro do próprio padrão de participação social, com um aprofundamento do projeto político democrático. Porém, a classe média teria, como sintoma desse impasse, passado a ganhar terreno e a se organizar de maneira diversa.

As manifestações de junho de 2013 marcariam, em Avritzer, a volta da separação entre participação institucionalizada e não institucionalizada e o fim do monopólio da participação social pela esquerda, fatos que inicialmente geraram uma 
pluralização da participação, abrindo espaço para que setores verbalizassem suas pautas nas manifestações que vinham ocorrendo ao longo do mês de junho.

Tanto Avritzer, quanto Santos, atribuem saldos positivos aos mecanismos de participação social implementados desde a redemocratização. Para Avritzer, os impasses democráticos também se fizeram sentir na esfera da participação social que, não obstante seus potenciais e saldos inclusivos, descuidou de setores como a classe média e de temas, como a infraestrutura. Essa lacuna é, em sua visão, o ponto de partida das manifestações de junho de 2013 , pois junho marcaria a volta da separação entre participação institucionalizada e não institucionalizada e o fim do monopólio da participação social pela esquerda. O que em princípio parecia ser um incentivo à pluralização da participação social, a partir do dia 17 passou a se esboçar enquanto "polarização", um processo que veio a transcender Junho. Encabeçado pelos setores da classe média, a polarização se caracteriza, cronologicamente, (a) pela perda de controle das manifestações de 2013 por parte do MPL (Avritzer, 2016a; 2017) - a proibição de bandeiras de partidos, a saída voluntária das ruas pelo MPL e a migração de questões relacionadas ao governo Dilma para a centralidade dos cliques e das ruas -; (b) pela ascensão e posterior fortalecimento de sites com agendas conservadoras (Avritzer, 2016a; 2017); (c) pelo acirramento da disputa eleitoral em 2014 (Avritzer, 2016b; 2017); (d) pelas manifestações de 2015, de agenda puramente negativa e, por isso, democraticamente lesiva (Avritzer, 2016a; 2016b); (e) pela americanização do exercício de oposição no Congresso Nacional (Avritzer, 2016b) que, centralizada na figura de Eduardo Cunha, determinou o impeachment (Avritzer, 2017).

Uma pergunta que atravessa as análises dos autores em tela (e de praticamente todos os intérpretes) sobre junho de 2013 poderia ser assim formulada: em que medida se pode vincular a forma dos protestos ao conteúdo da recusa das instâncias institucionais pelos manifestantes?

A forma das manifestações, tal como descrita por Santos (2013b, p.34), é típica das redes sociais. Criam-se redes de comunicação que alcançam indivíduos de diferentes "graus de separação" que não necessariamente possuem características 
política, ideológica e organizacional semelhantes entre si. Isso implica que essa forma de convocação específica conclamou às ruas pessoas sem vínculos consistentes, nem saldos organizativos prévios. É por esse motivo que, no início das manifestações, o que teria conectado os manifestantes uns aos outros não era qualquer pauta específica, mas sim uma emoção, a saber, a de "participar, protestar, se expressar, eventualmente de forma violenta, gritar palavras de ordem, portar cartazes, vestir máscaras, enfim, sentir a euforia de fazer parte de um movimento de massa de proporções inéditas" (Santos, 2013a, p.18; Santos, 2013b, p.35). Dessa forma, também para o cientista político, como já vimos acima para o caso da filósofa paulista, haveria uma proximidade entre a forma das manifestações de junho de 2013 e a "equação fascista": ambas são descomplexificadas. E mais, não falam a linguagem institucional das democracias: a forma dos protestos não soluciona os "dilemas informacionais" (2011), pois verbaliza pautas difusas que carecem de qualidade informacional, são lineares e arbitrárias; e a "equação fascista" (como o "pensamento mágico" criticado por Chauí) é hostil aos "dilemas de reconhecimento" (2011), justamente porque não reconhece a pluralidade de opiniões e orientações políticas. Teríamos, então, uma contradição-chave em um movimento que, ao mesmo tempo, revela-se absolutamente aberto à pluralidade de pautas e avesso a um pluralismo ideológico. A dispersão de pautas seria, em Santos, proveniente da própria forma de convocação.

Ao contrário de Santos, que enxerga essa recusa das instâncias institucionais como algo próprio das manifestações de junho de 2013, Fernando Haddad identifica um ator responsável por tal repulsa. Em entrevista com Bruno Torturra, Haddad (2017b), que em 2013 iniciava seu mandato como prefeito de São Paulo, defende que havia formas mais engenhosas de se atingir a revogação do aumento da tarifa de ônibus. Seria próprio de movimentos de esquerda como o MPL, contudo, recusar a negociação e a mediação com os poderes institucionais. Para Haddad, o que houve de mais importante nas manifestações de junho foi o "sequestro" da forma de organização do MPL pela direita: a forma de organização de um movimento de extrema esquerda teria fornecido os instrumentos e desencadeado um sentimento mais profundo de aversão à política, retroalimentado pelas mãos de setores de direita da classe média. 
Afinado com Santos, Haddad mostra como as políticas do governo Lula provocaram um mal-estar nas camadas médias tradicionais na medida em que alteraram sua posição relativa, distanciando-as dos ricos e aproximando-as dos pobres, que ascendiam. Esse descontentamento, durante muito tempo, não possuía meios tradicionais para se exprimir de maneira política. A "antipolítica" do MPL teria permitido, para Haddad, que a direita saísse às ruas e torcesse tal forma de organização em favor de pautas que atacavam o governo federal ${ }^{6}$.

As perspectivas de Santos e Haddad divergem no que diz respeito à natureza da recusa institucional nas manifestações de junho. Convergem, no entanto, na impressão de que havia um componente que é oposto à política, ou melhor, que nega a política. Mesmo que não usem os mesmos termos, a "equação fascista" de Santos equivale à "antipolítica" de Haddad, pois planifica a complexidade que envolve os processos representativos. Não compreender a ideia de que representação é também meio de participação significa, para Santos, que não se entende a forma como a política funciona. Mais ainda, a expressão de tal incompreensão recairia muitas vezes em contradição performativa, pois negaria a si mesma ao emitir o juízo de que todos os meios da política seriam corrompidos e não-efetivos.

Para Avritzer, presenciaríamos desde junho uma polarização na qual a classe média e suas pautas conservadoras e despolitizantes passam a determinar o conteúdo dos conflitos políticos. Analisando o imediato pós-junho, Avritzer detecta que ocorre uma mudança no padrão de participação social no país. Haveria um fator específico que teria possibilitado, desde Junho, um tipo de abertura política das ruas e a consequente reorganização dos setores conservadores no campo da participação social: a incapacidade do MPL de politizar o movimento. No início do mês de junho, o MPL predominava nas redes sociais e na organização do movimento. Seus posts mais

\footnotetext{
${ }^{6}$ Sobre a forma das organizações e sua potencial ambivalência, Pablo Ortellado (2013) afirma que junho de 2013 possui dois saldos: um que sobrevaloriza os processos e possui pautas muito difusas, perdendo de vista a orientação a resultados e, consequentemente, a natureza da política; e outro que defende princípios, mas sem perder de vista a ação estratégica e orientação a resultados. Em contraponto com os autores aqui analisados, Ortellado sai em defesa do modelo de ação do MPL, atribuindo a "sobrevalorização dos processos" ao momento posterior de difusão de pautas.
} 
visitados abordavam somente a proposta do movimento social, não havendo mobilização por qualquer pauta mais ampla. Com o passar dos dias, passou a se esboçar sintomas da polarização, como o surgimento e crescimento de perfis conservadores, responsáveis por trazer aquelas pautas despolitizantes para o centro das manifestações. É nesse sentido que Avritzer defende que Junho abriu espaço para a reorganização dos setores conservadores no país: primeiro na internet, e depois nas ruas.

Os anos posteriores a junho, como já dissemos, são marcados por uma crescente polarização e reorganização dos setores conservadores, liderados pela classe média. Os manifestantes que compuseram as manifestações de março de 2015 possuíam algumas características relevantes: boa parte deles reconhece sua presença nas manifestações de 2013, assim como tais "militantes" participavam mais de associações privadas, como associações profissionais, de vizinhança, de caridade e clubes de esporte, do que de formas de participação política direta comuns ao padrão de participação institucionalizada da Nova República. O novo padrão de participação social que se delineia no Brasil - mais próximo do modelo estadunidense (Avritzer, 2016a, p.42) - deixa de estar integrado ao Estado por meio de políticas públicas e instituições de participação, passando a atuar de maneira paralela às instâncias institucionais tradicionais; a participação, aqui, se formularia enquanto uma ferramenta "extra-institucional".

Ainda que a defesa de uma pauta negativa e a atribuição da corrupção ao partido governante sejam potencialmente despolitizantes, a descrição da conjuntura recente por Avritzer demonstra uma repolitização dos setores conservadores, ou seja, uma reorganização de setores que não encontravam meios de participação e mobilização desde 1964, mas que agora se aglutinaram em movimentos, pautas e objetivos, alterando o padrão de participação social. Há que se reparar, a nosso ver, que se trata de uma "repolitização" de tipo bastante específico, posto que a politização de setores conservadores não precisaria ser intrinsecamente golpista. Pode haver oposição visceral a políticas públicas implementadas por este ou aquele governo, e pode inclusive haver uma declarada reação à ascensão das classes 
subalternas, sem que este conteúdo antidemocrático determine como consequência necessária o atentado contra as instituições do país, construídas a duras penas desde os anos 1980. Parece-nos, pois, que a forma deste conservadorismo importa - e é importante lembrar, talvez na contramão da avaliação dos politólogos, que nem todo conservadorismo é golpista, assim como nem toda política feita nas ruas fragiliza a institucionalidade democrática. O risco de naturalizar o apego à institucionalidade como único canal propício à ação política respeitadora da democracia reside, talvez, em perder de vista a crise que seria, para boa tradição da filosofia política, intrínseca às tensões do nexo entre democracia e representação. A nossa crise, desde junho de 2013, passa também por aí - mas certamente não se resolveria com a tácita transformação do oximoro "democracia representativa" em mero pleonasmo (Rancière, 2014).

\section{Considerações finais}

Retomando os hegelianismos que constituíram nosso ponto de partida, tentamos observar certos modos de construção retórica da reação a junho de 2013 que, desde então, vem se consolidando como unilateralmente negativa tanto entre os autores estudados quanto em considerável fração da esquerda brasileira. A tentativa de "demorar-se no negativo" buscou não apenas lançar luz sobre as nuances internas à crítica ao componente conservador de junho, como também restituir o caráter marcadamente contraditório do fenômeno histórico. Assim como a mera apologia de junho de 2013 e a assunção imediata de um caráter transformador progressista na política multitudinária precisam cuidar-se para não soarem como variação esquerdista do auto-elogio, insuflado midiaticamente, de que "o gigante acordou"; também a crítica que mira o conservadorismo e trata imediatamente a política das ruas como sendo a antipolítica precisa cuidar-se para não recair na reificação institucional que subordinaria qualquer ímpeto de transformação ao ritmo lento, passivo, da burocracia estatal e da representação mediadora. Outro risco que, em alguma medida, ronda as perspectivas aqui analisadas consiste em avaliar junho de 2013 com o olhar 
excessivamente fixado no que ocorreu nos anos seguintes. Pois assim como é plausível censurar o viés do apologeta que insiste em desvincular fenômenos históricos cujo nexo é evidente, também é prudente atentar para o viés daqueles que, em nome da continuidade histórica, perdem de vista as especificidades, e virtualidades eventualmente abortadas, das manifestações.

A ênfase na negatividade dos eventos de junho revela ainda uma implicação de longo alcance. A confusão, aparentemente propositada, dos conceitos de conservadorismo, autoritarismo e fascismo pelos autores abordados reforça certo açodamento em suas análises, certa ânsia por desqualificar. Se o fascismo requer, tal como nos exemplos históricos dos anos 1920 e 1930, uma vinculação das massas a um líder carismático e uma aprovação popular massiva da "agenda fascista" que se expressa também nas urnas, é forçoso concluir que nada disso houve no Brasil de tempos recentes. A vinculação entre golpismo e fascismo é pouco acurada conceitual e historicamente (pode haver, e houve, fascismos sufragados eleitoralmente e golpismos de esquerda, vide o blanquismo), assim como é equivocamente dado como evidente o nexo entre autoritarismo e conservadorismo (pode haver, e houve, formas autoritárias de expansão da república e de modernização).

Quando Chauí e Santos, por exemplo, vinculam o suposto "elemento fascista" à recusa de mediações partidárias e a práticas violentas dos manifestantes, eles não fazem senão apontar para uma tendência possível da dinâmica política que explode em junho. Se a adjetivação carece de fundamento no que tange à descrição do evento específico, ela cumpre talvez um sentido de alerta para possíveis desdobramentos que já estariam postos na simbologia da luta verde-e-amarela contra a corrupção. Jessé Souza lança mão da imagem bergmaniana do "ovo da serpente" para caracterizar a mesma potencialidade, digamos, perturbadora. Há, contudo, efeitos políticos de tal viés de análise que exigem explicitação: tratar as manifestações in toto como fascistas impele ao abandono de qualquer relação de escuta das vozes das ruas e, mais do que isso, parece legitimar o estabelecimento de uma relação puramente repressiva contra manifestantes entendidos como inimigos da democracia. Em certo sentido, é possível que a unilateralidade analítica exposta ao longo deste artigo seja uma forma de 
expressão das dificuldades de largos setores da esquerda institucionalizada de lidar com aquelas manifestações.

Com a ajuda de Hegel, mais uma vez, vale lembrar que "a Coisa mesma não se esgota em seu fim, mas em sua atualização; nem o resultado é o todo efetivo, mas sim o resultado junto com o seu vir-a-ser. O fim para si é o universal sem vida, como a tendência é mero impulso ainda carente de sua efetividade; o resultado nu é o cadáver que deixou atrás de si a tendência" (Hegel, 1995, p. 22). Obnubilar-se com o cadáver deste "universal sem vida", deste resultado nu destituído das tendências que gestaram seu vir-a-ser, equivale a tomar o fim como se fosse o "todo efetivo". Porque a efetividade é a complexa combinação do resultado e do vir-a-ser, nosso intento foi chamar a atenção para a parcialidade do apego negativo ao suposto fim de junho de 2013, ressaltando sua contribuição para a devida compreensão histórica da política brasileira contemporânea - parcialidade correlata à daqueles, não estudados aqui, que se apegam às virtualidades e tendências, "meros impulsos ainda carentes de efetividade".

Sobre a necessidade de revisitarmos junho de 2013, e sublinhando o óbvio fato de que se trata, ainda e por muito tempo, de uma história em aberto, vale o célebre ensinamento benjaminiano: "o dom de despertar no passado as centelhas da esperança é privilégio exclusivo do historiador convencido de que também os mortos não estarão em segurança se o inimigo vencer. E esse inimigo não tem cessado de vencer" (Benjamin, 1985). Como vimos ao longo deste artigo, a dificuldade reside em discernir onde começa e onde termina este "inimigo". É possível, enfim, que um caminho profícuo, no plano analítico como no plano diretamente político, seja desconfiar, sem ilusões teleológicas, de que a derrota histórica esconda mais do que supõe o olhar acostumado a deter-se nos meros "resultados nus" - nesse sentido, o complemento preciso de Fredric Jameson assinala um ponto de chegada para este artigo. E, mais importante, indica um caminho para a revisita dialeticamente equipada da história: 
In history, indeed, the negative and the positive seem fatally to assume the form of success and failure, triumph and defeat, as though these categories, above and beyond the superficial, allegedly Hegelian illusions of teleology, offered the only ways in which biological human individuals could imagine the destiny of their collectivities. The dialectical union of these opposites is then a social rebuke as well as a political lesson. It reminds us, not only that 'success' was never really in the cards for the mortal beings in the first place, but also that history progresses, not by way of victory but by way of defeat: and that if our eyes are trained to see it, we can find this dialectic at work everywhere in the record of our collective existence (Jameson, 2010, p. 41).

\section{Referências Bibliográficas}

Alonso, A.; Mishe, A. 2016. Changing repertoires and partisan ambivalence in the new Brazilian protests. Bulletin of Latin American Research, p.1-16.

Alonso, A. 2017 A política das ruas. Novos Estudos: CEBRAP, v. Especial, p. 49-58.

Arantes, P. 2014. Depois de junho a paz será total. In: . O novo tempo do mundo. São Paulo: Boitempo, p.353-460.

Avritzer, L. 2016a. Os Impasses da Democracia no Brasil. 1. ed. Rio de Janeiro: Civilização Brasileira, v. 1., 153p .

2016b. Eleições, radicalização política e revolta social: uma análise do Brasil entre as eleições de 2014 e os panelaços de 2015. In: Fernando Mayorga. (Org.). Elecciones y legitimidad democrática en América Latina. 1ed.: CESU-UMSS/CLACSO/IESE/Plural editores, p. 39-57.

2017a. Participation in democratic Brazil: from popular hegemony and innovation to middle-class protest. Opinião Pública (UNICAMP), v. 23, p. 43-59.

2017b. The Rousseff impeachment and the crisis of democracy in Brazil. Critical Policy Studies, v. 11, p. 352-357.

Benjamin, W. 1985. As Teses sobre o Conceito de História. In: Obras Escolhidas, Vol. 1, São Paulo: Brasiliense, p. 222-232.

Bringel, B.; Pleyers, G. 2015. Junho de 2013? dois anos depois: polarização, impactos e reconfiguração do ativismo no Brasil. Nueva Sociedad, v. 259, p. 4-17.

2017. Crisis política y polarización en Brasil: de las protestas de 2013 al golpe de 2016. In: Breno Bringel; Geoffrey Pleyers. (Org.). Protesta e indignación global: los movimientos sociales en el nuevo orden mundial. 1ed. Buenos Aires: CLACSO, v., p. 135-148.

Bucci, E. 2016. A forma bruta dos protestos. 1a. ed. São Paulo: Companhia das Letras, v. 1., $178 p$.

Castells, M. 2013. Redes de indignação e de esperança. São Paulo: Zahar. 
Chauí, M. S. 1986. Conformismo e resistência. Aspectos da cultura popular. São Paulo: Brasiliense.

2013a. Manifestações ideológicas do autoritarismo brasileiro. São Paulo: Ed. Fundação Perseu Abramo.

. 2013b. Entrevista: O efeito das manifestações. In: Caros Amigos. São Paulo, n. 182.

2013c. Uma nova classe trabalhadora: indagações. In: Fundação Perseu Abramo e Fundação Friedrich Ebert (org.). Classes? Que Classes?. São Paulo: Fundação Perseu Abramo e Fundação Friedrich Ebert, p.87-103.

2013d. As manifestações de junho de 2013 na cidade de São Paulo. Disponível em: < http://www.teoriaedebate.org.br/materias/nacional/manifestacoes-de-junho-de-2013-nacidade-de-sao-paulo?page=full >. Acesso em: 27/06/2013.

2016. "A nova classe trabalhadora brasileira e a ascensão do conservadorismo". In: Ivana Jinkings (org.). Por que gritamos golpe? Para entender o impeachment e a crise política no Brasil. São Paulo: Boitempo.

Haddad, F. 2017a. Vivi na pele o que aprendi nos livros. Revista Piauí, p. 28 - 37, 05 jun.

- 2017b. Fernando Haddad: a catarse e a ressaca política. Disponível em: $<$ https://www.youtube.com/watch?v=3qXnX2ng|Y0>. Acesso em: 23 out.

Hegel, G.W.F. 1995. Fenomenologia do espírito. Petrópolis: Vozes.

Jameson, F. 2010. The valences of the dialectic. Londres: Verso.

Moraes, A; et al. 2014. In: Souza, A. M.; et al (Org.). Junho: potência das ruas e das redes. 1ed. São Paulo: Friedrich Ebert Stifung, v. 1, p. 10-21.

Negri, A.; Hardt, M. 2004. Multitude. Nova lorque: Penguin.

Neri, M. 2010. A nova classe média: o lado brilhante dos pobres. RJ: FGV.

Nobre, M. 2013. Choques de democracia: razões da revolta. São Paulo: Ed. Schwarcz, 33p.

Ortellado, P. 2014. Os protestos de junho entre o processo e o resultado. In: ORTELLADO, P; POMAR, M. ; LIMA, L. ; JUDENSNAIER, E. Vinte centavos: a luta contra o aumento. 1. ed. São Paulo: Veneta, 240p.

Pogrebinschi, T.; Santos, F. G. M. 2011. Participação como representação: o impacto das conferências nacionais de políticas públicas no Congresso Nacional. Dados (Rio de Janeiro), v. 54, p. 21-47.

Rancière, J. 2014. O ódio à democracia. São Paulo: Boitempo.

Safatle, V. P. 2017. Só mais um esforço. 1. ed. São Paulo: Três Estrelas, 144p.

Santos, F. G. M. 2013a. Do protesto ao plebiscito: uma avaliação crítica da atual conjuntura brasileira. Novos Estudos: CEBRAP, v. 96, p. 15-25. 
. 2013b. Primavera Brasileira ou Outono Democrático?. Insight Inteligência (Rio de Janeiro), v. 16, p. 32-38.

Singer, A. 2013. Brasil, junho de 2013: classes e ideologias cruzadas. Novos Estudos: CEBRAP, São Paulo, n.97.

Souza, J. 2000. Modernização seletiva. Brasília: UnB.

2003. A construção social da subcidadania. Belo Horizonte: UFMG.

2009. Os batalhadores. Belo Horizonte: UFMG.

2015. A tolice da inteligência brasileira. RJ: LeYa, 2015.

2016. A radiografia do golpe. RJ: LeYa.

2017. A elite do atraso. RJ: LeYa.

Tatagiba, L. 2014. 1984, 1992 e 2013: sobre ciclos de protestos e democracias no Brasil. Revista Política e Sociedade, UFSC, vol. 13, n. 28.

Tatagiba, L,; Teixeira, A. C. C.; Trindade, T. A. 2015. "Protestos à direita no Brasil (20072015)". In: Sebastião Velasco e Cruz; Andre Kaysel; Gustavo Codas. (Org.). Direta volver! O retorno da direita e o ciclo político brasileiro. 1ed.São Paulo: Fundação Perseu Abramo, 2015, v. 1, p. 197-213.

Vianna, L. W. 1999. "Weber e a interpretação do Brasil". In: J. SOUZA (org.), O malandro e o protestante: a tese weberiana e a singularidade cultural brasileira. Brasília: UnB, p. 173-194.

Tramitação do artigo na revista Submetido: 15/06/2018

Revisões requeridas: 15/07/2018

Versão revista: 17/08/2018

Aceito: $24 / 09 / 2018$ 